\title{
Comparison of Pressor Response Elicited by Talwalkar Fibrelite Stylet (TFS) Versus Direct Laryngoscopic Technique for or tracheal Intubation in Adult Patients Undergoing General Anaesthesia
}

\author{
Sanjeevani Zadkar ${ }^{1}$, R D Patel ${ }^{1}$, Arti Kulkarni ${ }^{1}$, Yogesh Rathod ${ }^{2}$ \\ ${ }^{1}$ Assistant Professor, Department of Anaesthesiology and Critical Care, \\ Seth G S Medical College \& KEM Hospital, Mumbai, India. \\ ${ }^{1}$ Professor, Department of Anaesthesiology and Critical Care, \\ Seth G S Medical College \& KEM Hospital, Mumbai, India \\ ${ }^{1}$ Associate Professor, Department of Anaesthesiology and Critical Care, \\ Seth G S Medical College \& KEM Hospital, Mumbai, India \\ ${ }^{2}$ Student, MD Anaesthesia, Department of Anaesthesiology and Critical Care, \\ Seth G S Medical College \& KEM Hospital, Mumbai, India.
}

\begin{abstract}
Direct laryngoscopy is well proven and most commonly used technique of orotracheal intubation. Lighted stylet device is also an established technique of orotracheal intubation. Talwalkar's fibrelite stylet is a type of lighted stylet deviced for orotracheal intubation. This study compares pressor response elicited by Talwalkar Fibrelite Stylet (TFS) Versus direct laryngoscopic technique for orotracheal Intubation in adult patients undergoing general anaesthesia

Materials \& Methods: Hundred patients were randomized to undergo tracheal intubation with either the Talwalkar fibrelite stylet (TFS group, $n=50$ ) or the direct laryngoscope (LS group, $n=50$ ). Intubation was attempted with the assigned airway device. The data collected included the rate of successful endotracheal intubation, the number of attempts required, the duration of the intubation, as well as adverse effects.

Statistical Analysis: The statistical analysis of the study was carried out by using ANOVA application, Chi square test, (Pearson Chai square test.) wherever applicable.

Results: In laryngoscopy group 45(95\%) intubations were successful in first attempt, while 5(10\%) required second attempt. In TFS group 30(60\%) intubations were successful in first attempt and 20 (40\%) required second attempt. The duration of successful intubation for the first tracheal intubation attempt was comparable in both groups. All intubations were completed successfully within two intubation attempt.

Conclusions: As compared to conventional direct laryngoscopy, TFS is associated with lesser degree of pressor response during intubation, hence it can be safe \& effective device of intubation.
\end{abstract}

Keywords: laryngoscopy, intubation, Talawalkar fibrelite Stylet, pressor response, general anaesthesia

\section{Introduction}

Modern methods of tracheal intubation (TI) emerged in the 20th Century ${ }^{1}$ It is estimated that $1-3 \%$ of the surgical patients s, $^{1,2,5}$ and $0.05 \%$ to $3.5 \%$ of obstetric patients ${ }^{1,3,2,5}$ have difficult airway making direct vision laryngoscopic intubation difficult. This is especially true in patients requiring emergency tracheal intubation. ${ }^{1,3}$ Furthermore; there is not a single method of airway assessment that can be used reliably to predict a difficult laryngoscopic intubation ${ }^{4,5,6}$. Over the years, alternative intubation techniques have been developed to successfully intubate the trachea and thereby provide useful alternatives to the standard technique of intubation using the laryngoscope. One of these devices is the lightwand.

Light-guided intubation using the principle of transillumination has proven to be an effective and simple technique ${ }^{4}$. When the tip of the lightwand is placed inside the glottis, a bright light glow can be seen easily in the soft tissue of the anterior neck. In contrast, if the lightwand is placed in the esophagus, no transillumination can be observed. . Previous studies have proven the efficacy of the lightwand as a safe and effective device to intubate the trachea of elective surgical patients with difficult airway. ${ }^{2,3,4,5,7}$ Since the lightwand technique of intubation does not involve lifting of the epiglottis it was expected to reduce the pressor response to endotracheal intubation as compared to direct laryngoscopy. Also, since it is a gentle technique not involving much manipulation of the soft tissues the incidence of sore throat and mucosal injuries are also reported to be lesser than that following laryngoscopic intubation. ${ }^{2}$ Avoidance of pressor response efficaciously 
remains the catch for good anaethetic management while induction and intubation. This study compares pressor response elicited by Talwalkar Fibrelite Stylet (TFS) Versus direct laryngoscopic technique for orotracheal Intubation in adult patients undergoing general anaesthesia.

\section{Materials and Methods}

After obtaining approval from our hospital research \& ethics committee and written informed consent from each patient, 100 adult patients undergoing general anesthesia for elective operation were selected on the basis of inclusion criteria.

\section{Inclusion criteria:}

1. Age - 18-60yrs., 2. ASA - I, II., 3. MPC - I, II., 4. Mouth opening $>3.5 \mathrm{~cm}$,

5. Neck movements - Normal.

6 . Thyromental distance $\geq 6.5 \mathrm{~cm}$

Detailed preanesthetic evaluation was done prior to surgery.

\section{Exclusion criteria:}

Cervical spine abnormality or disease.

Mouth opening $<3.5 \mathrm{~cm}$.

Oral cavity tumors, abscess, space occupying lesions distorting pharyngeal anatomy.

ASA grade more than III, IV

Pregnant patients

They were randomly divided into 2 groups by means of sealed envelopes

Group I-orotracheal intubation was achieved with Macintosh laryngoscope with the patient's head, neck in the conventional sniffing position.

Group II- Orotracheal intubation was performed with the TFS with the patient's head in sniffing position.

All 100 patients were premedicated with Inj. Glycopyrrolate $4 \mathrm{mcg} / \mathrm{kg}$ i. m. $30 \mathrm{~min}$ prior to operation. The anesthetic technique was standardized. All baseline parameters including heart rate, blood pressure and oxygen saturation were recorded. The patients were administered i.v midazolam $0.03 \mathrm{mg} / \mathrm{kg}$ along with i.v fentanyl $2 \mu \mathrm{g} / \mathrm{kg} 5$ minutes prior to induction of anesthesia. Patients were then preoxygenated for 3 minutes followed by induction with inj. Propofol 1.5 to $2.5 \mathrm{mg} / \mathrm{kg}$. inj. Vecuronium was used as muscle relaxant in dose $0.1 \mathrm{mg} / \mathrm{kg}$ After adequate muscle relaxation and adequate depth of anesthesia achieved, patient was intubated according to the group allocated. The Macintosh laryngoscope blades used were number-3 for females and number- 4 for males. Tracheal tubes (portex) with an internal diameter of $7 \mathrm{~mm}$ were used for female patients and $8 \mathrm{~mm}$ for male patients.

Technique:

Group A: Macintosh laryngoscope was introduced through mouth opening. Tongue was taken to the left side with help of laryngoscope blade. Tip of blade was advanced under vision to the base of epiglottis which was lifted up with help of handle movement of laryngoscope. Vocal cords were visualized and endotracheal portex tube of appropriate size was passed through the cords in the trachea.

Group B: In light wand guided intubations, lighted stylet was used. It is malleable stylet with fibreoptic light, creating a glow at tip. Light in theatre was made dim. The principle used was transillumination. Endotracheal tube was threaded over it. Light wand was also introduced orally over tongue in the midline. Then it was taken to either right or left sided pyriform fossa, glow was seen on respective lateral side of neck at the level of hyoid cartilage. Then the TFS was withdrawn and glow was centralized. It was advanced further with help of glow seen in midline, in the anterior neck. When the tip enters the glottic opening, a well circumscribed glow can be seen in the anterior neck slightly below the thyroid prominence. The tube was advanced until the glow appears at the sternal notch, then the stylet was withdrawn and tube position confirmed. Patient was ventilated with $100 \%$ oxygen for one min. in between two attempts. Tube position was confirmed with $\mathrm{ETCO}_{2}$. Anesthesia was then maintained as per routine hospital protocol. Failure to intubate was defined as inability to intubate the trachea successfully even in 3 attempts. Hemodynamic parameters were recorded at the following periods:

1. Baseline heart rate, $\mathrm{BP}$

2. at insertion of device into oral cavity

3. Immediately following intubation

Anaesthesia was then maintained as per requirement of the surgical procedure Hemodynamic parameters like heart rate, $\mathrm{BP}$ were recorded throughout perioperative period.

In the postoperative period the patients were monitored by an investigator blinded to the procedure used for achieving intubation for sore throat, hoarseness of voice, mucosal injuries etc.at $0 \mathrm{~min}$, $6 \mathrm{hrs}$ and $24 \mathrm{hrs}$. 
Comparison of clinical efficacy of talwalkar fibrelite stylet (TFS) versus direct laryngoscopic...

\section{Statistical Analysis}

The statistical analysis of the study was carried out by using ANOVA application, Chai square test, (Pearson Chai square test.) wherever applicable.

\section{Results}

Parameters like number of patients, age distribution(yrs), sex distribution were comparable in both groups. Airway parameters like mean thyromental distance, mean inter-incisor distance, MPC grading, ASA status was also comparable in both study groups. It was seen that all 50 intubations in LS group were done by anaesthesiologists who were having experience of minimum 100 intubations with LS. In LW group all 50 intubations were done by anaesthesiologists who were having experience of less than 6 intubations with LW. The difference in experience level of anaesthesiologists in both groups is significant. Experience level was more in LS group that LW group. The mean pre operative pulse rate in laryngoscope group was $75.90 \pm 7.856$ per min. That in lightwand group was $73.96 \pm 6.465$ per min. The statistical difference is not significant. The mean pulse rate at insertion of LS into oral cavity was $82.56 \pm 8.636$ per min. The mean pulse rate at insertion of LW into oral cavity was $78.12 \pm 6.530$ per min. The statistical difference is significant as p value is .004 The mean pulse rate immediately after intubation in laryngoscope group was $99.46 \pm 8.917$ per min. That in lightwand group was $92.90 \pm 5.632$ per min. When both groups LS and LW are compared, the statistical difference is significant as $p$ value is 0.000 . The mean pre operative SBP in laryngoscope group was $112.44 \pm 6.185 \mathrm{~mm}$ of $\mathrm{Hg}$. That in lightwand group was $114.16 \pm 10.043 \mathrm{~mm}$ of $\mathrm{Hg}$ The statistical difference is not significant. The mean SBP at insertion of LS into oral cavity was $122.12 \pm 5.889 \mathrm{~mm}$ of $\mathrm{Hg}$. The mean SBP at insertion of LW into oral cavity was $122.72 \pm 9.737 \mathrm{~mm}$ of $\mathrm{Hg}$. The statistical difference is significant as $\mathrm{p}$ value is .004 . The mean SBP immediately after intubation in laryngoscope group was $141.16 \pm 7.603 \mathrm{~mm}$ of $\mathrm{Hg}$. That in lightwand group was $132.48 \pm 10.533 \mathrm{~mm}$ of $\mathrm{Hg}$. When both groups LS and LW are compared, the statistical difference is significant as $\mathrm{p}$ value is 0.000 . The mean pre operative DBP in laryngoscope group was $112.44 \pm 6.185 \mathrm{~mm}$ of $\mathrm{Hg}$. That in lightwand group was $114.16 \pm 10.043 \mathrm{~mm}$ of $\mathrm{Hg}$ The statistical difference was not significant.

Graph no. 1: Comparison of pulse rate in both groups:

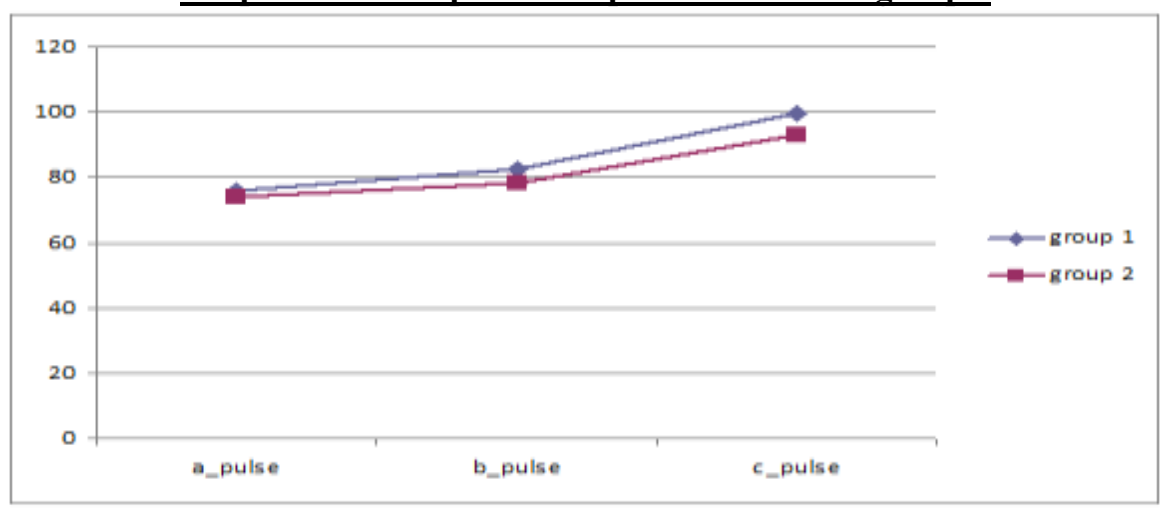

The mean DBP immediately after intubation in laryngoscope group was $141.16 \pm 7.603 \mathrm{~mm}$ of $\mathrm{Hg}$. That in lightwand group was $132.48 \pm 10.533 \mathrm{~mm}$ of $\mathrm{Hg}$ When both groups LS and LW are compared, the statistical difference is significant as p value is 0.000 The mean DBP at insertion of LS into oral cavity was $122.12 \pm$ $5.889 \mathrm{~mm}$ of $\mathrm{Hg}$. The mean DBP at insertion of LW into oral cavity was $122.72 \pm 9.737 \mathrm{~mm} \mathrm{of} \mathrm{Hg}$. The statistical difference is significant as $\mathrm{p}$ value is .004 . The mean pre operative saturation in laryngoscope group was $99.32 \pm$ .471 . That in lightwand group was 99.62 \pm .490. The statistical difference is not significant. The mean saturation at insertion of LS into oral cavity in laryngoscope group was $99.32 \pm 0.471$. That in lightwand group was $99.62 \pm$ .490. The statistical difference is not significant.

The mean saturation immediately after intubation in laryngoscope group was $99.32 \pm 0.471$. That in lightwand group was $99.62 \pm .490$. The statistical difference is not significant. It was seen that all 50 intubations in LS group were done by anaesthesiologists who were having experience of minimum 100 intubations with LS. In LW group all 50 intubations were done by anaesthesiologists who were having experience of less than 6 intubations with LW. The difference in experience level of anaesthesiologists in both groups is significant. Experience level was more in LS group that LW group. It was found that the incidence of complications is more with laryngoscopy group as compared to lightwand group. In laryngoscopy group out of 50 patients 5 patients had post of sore throat. Mucosal injury was found in 5 patients. Two patients had oesophageal intubation in laryngoscopy group. In lightwand group no patient developed sore throat or had mucosal injury. Intubation was endobronchial in 5 patients in laryngoscopy group. No patient in lightwand group had end bronchial intubation 
Graph no: 2 Comparison of systolic blood pressure in both groups:

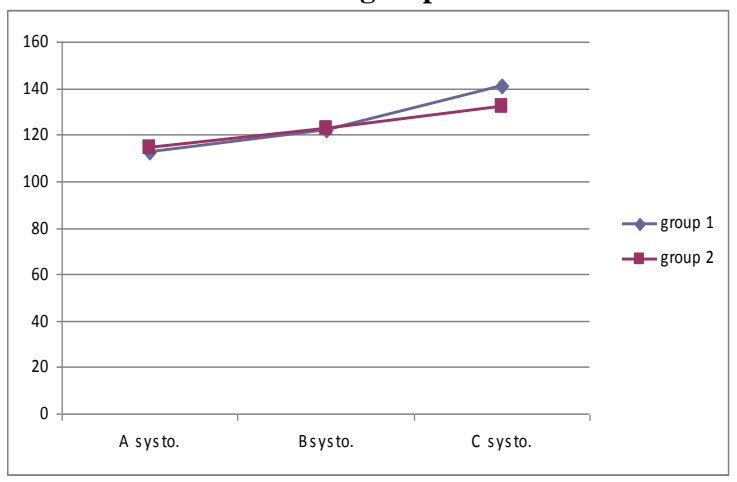

Graph no: 3 Comparison of diastolic blood pressure in both groups:

Figure 1: Talwalkar Fibrelite Stylet (TFS)

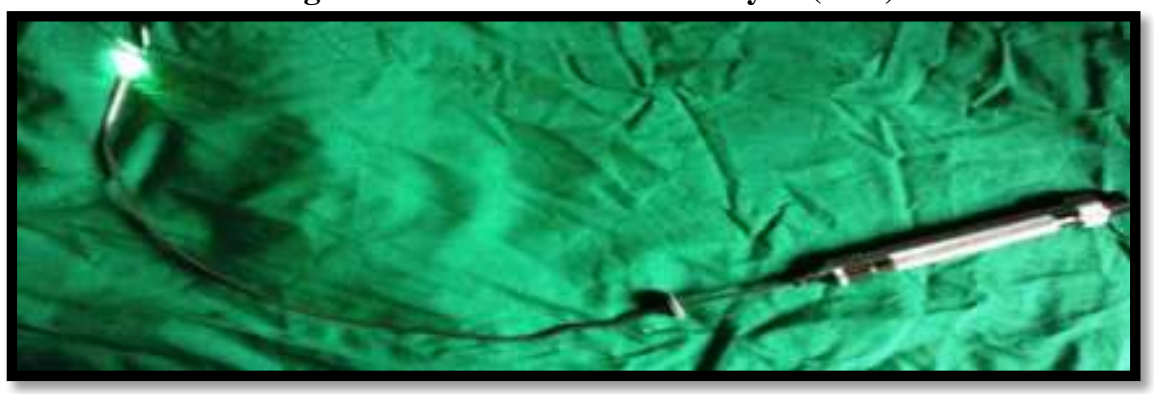

IV. Discussion

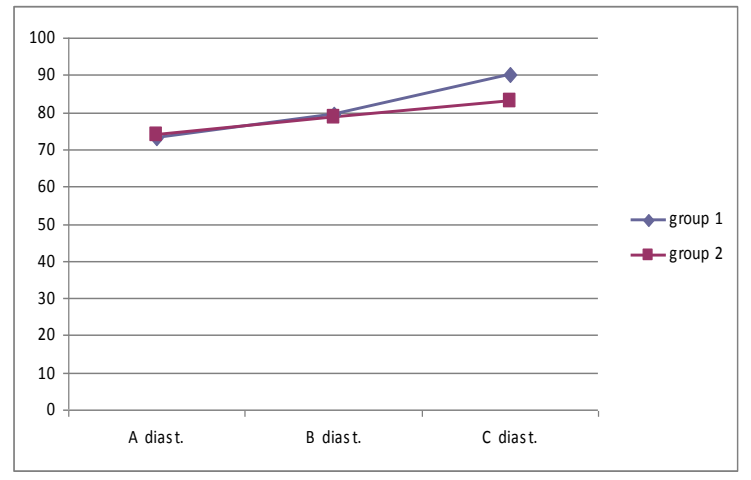

Most of the other comparative studies have used Trachlight as a lightwand device ${ }^{[10,11,13]}$. Our study compared Talwarkar`s fibrelite stylet by Anaesthetics with direct laryngoscopy. Talwalkar`s fibrelite stylet has advantages of being cheap and easily available. It is simple to use and assemble. The lightwand technique of intubation does not involve lifting of the epiglottis which is the reason of reduced the pressor response to endotracheal intubation as compared to direct laryngoscopy. It comparately gentle technique of intubation. The lightwand group had a significantly lower incidence of traumatic complications like mucosal injury, lip trauma, tooth fall so lower incidence sore throat, hoarseness in the postoperative period Tip of the TFS is not flexible and its movement cannot be controlled from outside. This causes increased need of maneuvering during intubation that explains the significantly more intubation time in TFS group. The TFS group had a significantly lesser degree of pressor response in terms of tachycardia or hypertension. Overall success rate in both groups is comparable. Success rate at first attempt in TFS group are significantly less than the number of intubation attempts in LS group. ${ }^{11}$

\section{Conclusion}

TFS is better at avoiding pressor response than normal laryngoscopy. Pressor response to lightwand intubation is less than laryngoscopic intubation even with non experienced staff.

\section{References}

[1]. Hung OR, Stewart RD. Illuminating stylet (lightwand). In: Benumof JL (Ed.). Airway Management, Mosby, 1996: 342-52.
[2]. Hung OR, Pytka S, Morris I, Murphy M, Stewart RD. Lightwand intubation: II . Clinical trial of a new lightwand for tracheal intubation in patients with difficult airways. Can J Anaesth 1995; 42: 826-30.
Agro F, Hung OR, Cataldo R, et al. Lightwand intubation using the Trachlight: a brief review of current knowledge. Can J Anaesth 2001; 48: 592-9.

Agro F, Hung OR, Cataldo R, et al. Lightwand intubation using the Trachlight: a brief review of current knowledge. Can J Anaesth 2001; 48: 592-9.
Hung OR, Pytka S, Morris I, et al. Clinical trial of a new lightwand device (Trachlight) to intubate the trachea. Anesthesiology 1995; 83: 509-14

Hung OR, Pytka S, Morris I, et al. Clinical trial of a new lightwand device (Trachlight) to intubate the trachea. Anesthesiology $1595,83.509-14$
J Anesth Clin Pharmacology 2007; 23(1): 53-58 A Comparison of Clinical Efficacy of Lightwand (Trachlight) V/S Direct Laryngoscopy for Orotracheal Intubation , J Anesth Clin Pharmacology 2007; 23(1): 53-58 A
Shrikanth Srinivasan, C.K. Dua, Kirti Nath Saxena

Hung OR, Al-Qatari M. Light-guided retrograde intubation. Can J Anaesth 1997; 44: 877-82

Hung OR, Stewart RD. Lightwand intubation: I - A new ligthwand device. Can J Anaesth 1995; 42: 820-5

Hirabayashi Y, Hiruta M, Kawakami T, et al. Effects of lightwand (Trachlight) compared with direct laryngoscopy on circulatory responses to tracheal intubation. Br J Anaesth 1998; 81:253.

Kihara S, Brimacombe J, Yaguchi Y, Watanabe S, Taguchi N, Komatsuzaki T. Hemodynamic Responses Among Three Tracheal Intubation Devices in Normotensive and Hypertensive Patients. Anesth Analg 2003;96:890 -5

Soh C R, Kong CF. Tracheal intubation by novice staff: the direct vision laryngoscope or lighted stylet (Trachlight)? Emerg Med J. 2002 Jul;19 (4):292-4

[11]. Nishikawa K, Omote K, Kawana S, Namiki A. A comparison of hemodynamic changes after endotracheal intubation by using the lightwand device and the laryngoscope in normotensive and hypertensive patients. Anesth Analg 2000; 90: 1203-7

Shrikanth Srinivasan, C.K. Dua, Kirti Nath Saxena. A Comparison of Clinical Efficacy of Lightwand (Trachlight) V/S Direct Lar yngoscopy for Orotracheal Intubation, J Anesth Clin Pharmacology 2007; 23(1): 53-58

Takahashi S, Mizutani T, Miyabe M, Toyooka H. Hemodynamic Responses to Tracheal Intubation with Laryngoscope Versus Lightwand Intubating Device (Trachlight(R)) in Adults with Normal Airway, Anesth. Analg., August 1, 2002; 95(2): 480 - 484. 